cerns, in the end, above environmental ones, shaped the negotiations. Environmental protection mechanisms were weakened in the search for agreement on political and legal issues' (page 153). In the second case, 'the dominance of sovereignty norms within the regime once again placed limits on what states would accept in terms of monitoring and enforcement institutions and rules. Thus their ability to ensure compliance must be questioned' (page 153). The internal accommodation of CRAMRA did not finally hold, the author concludes, because it became increasingly unacceptable that a regulatory mechanism could also function as a conservation and environmental protection regime.

Chapter 7 traces the more recent events leading to the abandonment of CRAMRA and the negotiation of the Madrid Protocol. It is argued that both these developments cannot be understood through the conventional statecentric, power-political explanations. The coalitions that arose to mobilise change in the Treaty regime were not just between states; they were between states and other actors. The impact of environmental NGOs on the institutional bargaining process was thus substantial. While referring to SCAR, Elliott points out that 'whereas NGOs were influential actors (as a source of new ideas and in generating support for these ideas), the scientific community did not function in this process as an epistemic community (in policy advocacy) nor even successfully in support of its own interests in the regime. In this respect, the scientific community and NGOs were in competition for influence and power within the Treaty System' (page 195).

Chapter 8 offers a brief assessment of the Protocol as an environmental protection agreement. While considerable uncertainty surrounds the Protocol's future, especially its effective implementation, the Protocol has brought about a qualitative change in the approach to environmental issues in the Antarctic regime. The balance of participation and knowledge, which in the past has favoured the consultative parties and bureaucratic actors, can no longer exclude NGOs. That said, the claim cannot yet be that interdependence norms have replaced sovereignty norms within the ATS. Although some change is noticeable in the hierarchy of values, "we have not observed a paradigm shift in the Antarctic regime' (page 210).

To sum up: an excellent book. A highly original, thought-provoking, and forcefully argued case study in international environmental politics. It is highly recommended to all with interests in the Antarctic. It will also be an important text for students and researchers in environmental management and environmental politics. (Sanjay Chaturvedi, Department of Political Science, Panjab University, Chandigarh 160014 , India.)

THE VOYAGES OF THE 'MORNING'. Gerald S. Doorly. 1995. Banham: Bluntisham Books and the Erskine Press. $x x+224 p$, illustrated, hard cover. ISBN 1-85297040-5. £24.95; \$US45.00.

Crucial to the safe return of Captain Robert Falcon Scott's ship Discovery, beset in the ice of McMurdo Sound, were the two relief expeditions, the first in 1903 in Morning, the second in 1904, again in Morning, accompanied by Terra Nova. No official account of these expeditions has ever appeared in print other than a brief report in the Geographical Journal (23: 741-744) by Morning's captain, William Colbeck. It was left to a junior officer on Morning, Gerald Doorly, to fill the gap. According to Doorly, the idea of a book had originally been put to Lieutenant E.R.G.R. (Teddie) Evans by Sir Arthur Conan Doyle, to be written with Doorly's cooperation. In the event, Evans had to drop out, and it was left to Doorly to produce, as late as 1915, a draft that he duly sent to Sir Clements Markham, 'father' of the Discovery expedition and owner and manager of Morming. In a letter to the publisher Reginald Smith, Sir Clements commended Doorly's draft as 'pleasantly written - first impressions of a keen observer...The whole story is well told.' He was also agreeable to providing an introduction, but, alas, this was prevented by his sudden and tragic death. The book was published the following year, 1916, by Smith, Elder.

In his opening chapters, Doorly describes how his golden opportunity to voyage south was occasioned by his friendship with Teddie Evans. As cadets on the training ship Worcester, the two youngsters had become inseparable chums. Subsequently they were destined to go their own ways, Evans into the Royal Navy, Doorly into the Merchant Service. Both kept regularly in touch until one day in June 1902 Doorly received a telegram from his friend suggesting he should immediately apply to join an Antarctic relief expedition. The prospect of adventure was not to be resisted and Doorly hastened to London to stake his claim. Following a favourable interview with Markham, Doorly found himself appointed third officer on Morning, with Evans as second officer. The ship set sail for the Ross Sea via New Zealand on 9 July 1902, only marginally delayed by the unexpected delivery of a last-minute gift from Markham - a brand new piano. Doorly gives an amusing account of how, having failed to manoeuvre the precious instrument into Morning's tiny wardroom, Morrison, the chief engineer, proceeded to resolve the dilemma by cutting it in half with a hacksaw! The importance of music as a morale booster on a polar expedition cannot be over-emphasised; Morrison's flair for verse coupled to Doorly's ability to compose music produced the 'Songs of the Morning,' two of which are reproduced in this volume with their scores.

Notwithstanding its period style, with echoes of G.A. Henty and R.M. Ballantyne, Doorly tells his story with a verve and pace that make for compelling reading. His firsttime impressions of the Antarctic scene evidence a keen sensitivity to natural beauty, which in places bears comparison with Edward Wilson's journal entries a year previously. Equally refreshing is the complete absence of rancour and criticism of superiors; Evans he obviously hero-worshipped; Colbeck, an experienced ice-master, he much respected. As for Scott, 'that gallant officer and ideal leader,' he has nothing but praise. In February 1903, 
following the welcome arrival of Morning, a party was held on board Discovery to celebrate the safe return of Scott, Wilson, and Shackleton from the far south. All three had suffered terribly from exposure and scurvy, Wilson and Shackleton being confined to their cabins. All had ravenous appetites. At dinner only Scott felt able to take his place at table, gorging himself on quantities of food and from time to time surreptitiously stealing into his colleagues' cabins with fresh supplies. After everyone had finally retired to their bunks, Doorly reports being awakened by Scott rousing Shackleton with the words: 'I say, Shackleton, how would you fancy some sardines on toast?' Was their relationship as strained as some would like to imagine?

In 1904, Discovery was visited a second time by Morning, which was attended by Terra Nova, and, with the aid of nature and guncotton, was released from her prison of ice. Following the expedition's triumphant return to England, Doorly bade farewell to his comrades and in 1905 emigrated to New Zealand, settling down as a captain of coastal and passenger ships. He continued to write, publishing a collection of his short stories under the title In the wake (1936) and The songs of the Morning (1943). He died in 1956. Bluntisham Press and its editor, D.W.H. Walton, are to be congratulated on a welcome addition, well-bound in a facsimile of the original boards, to their growing list of out-of-print polar titles. (H.G.R. King, Scott Polar Research Institute, University of Cambridge, Lensfield Road, Cambridge CB2 1ER.)

\section{RECKONING WITH THE DEAD: THE LARSEN BAY REPATRIATION AND THE SMITHSONIAN INSTITUTION. T.L. Bray and T.W. Killion (Editors). 1994. Washington and London: Smithsonian Institution Press. xiv + 194 p, illustrated, soft cover. ISBN 1-56098- 365-5. £23.25; US\$35.95.}

Larsen Bay is situated on Kodiak Island, adjacent to the Alaska Peninsula, and therefore close to the presumed route of entry of humans to North America. During the early 1930s, the native cemetery at Larsen Bay was excavated by $\mathrm{Dr}$ Ales Hrdlicka, curator at the Smithsonian Institution. In 1987, the Larsen Bay Tribal Council made a formal request for the return of all materials excavated by Hrdlicka and deposited in the Smithsonian Museum. At that time, Smithsonian policy only acknowledged rights of lineal descendants to burial remains (Donald J. Ortner's contribution to the volume traces the history of this policy), yet many of the Larsen Bay burials were more than 1000 years old. Few established administrative procedures existed in the Smithsonian through which a response could be co-ordinated. The Institution's initial reply was to argue that the community had given its assent to the excavations at the time, and that its present interests could not take precedence over 'the benefit to all people' of retaining the skeletons and grave goods in the Smithsonian.

During the course of negotiations about their return two crucial laws were passed, the 1989 National Museum of the American Indian Act and the 1990 Native American
Graves Protection and Repatriation Act. The first requires that material be returned if the 'tribe of origin' can be identified; the second requires demonstration of 'cultural linkage' between those whose remains are at issue and those demanding their return. Lynne Goldstein argues that, since the Larsen Bay Council requested return of the material before the passage of the two Acts, its repatriation does not set a legal precedent. Nonetheless, the later stages of negotiation were conducted in the knowledge that the new laws demanded a change of museum policy, since they would ultimately require the return of up to $25 \%$ of the Smithsonian's collections. The Larsen Bay petition led to new procedures for identifying and deaccessioning grave goods held by the Institution, and the establishment of a Repatriation Review Committee.

Although biological and cultural research is needed to resolve the questions of genetic and cultural continuity, such research will have both scholarly and pragmatic implications when it is conducted in such a context. Culture itself, as Tamara Bray and Lauryn Grant point out, ceases to be purely a technical term of anthropology and acquires a legal standing, as became the case with the terms 'local descent group' and 'traditional owner' in the Northern Territory of Australia after passage of the Aboriginal Land Rights Act of 1976 (see Layton 1985).

Hrdlicka's principal method was to collect and measure human skulls. He was insensitive to the feelings of living peoples. In keeping with the ethos of nineteenthcentury colonisers, he assumed native peoples would either die out or become assimilated. He took it for granted that they had been severed from their pre-colonial past, which had become 'prehistory.'

At the time it received the Larsen Bay Council's resolution, the Smithsonian had already gained experience of returning cultural material, through its negotiations with the Zuni (Merrill and others 1993). Even though the decision to return Hrdlicka's collection was eventually taken by the Secretary of the Smithsonian without reference to experts' research findings, both the community and the Smithsonian commissioned outside experts to collect and evaluate evidence for the extent of biological and cultural affiliations between the living people of Larsen Bay and those who had been buried there. Tamara Bray and Thomas Killion's volume presents the results of the research carried out by archaeologists and biological anthropologists for both sides, showing them to be essentially in agreement. It draws conclusions from the processes that led to the collection's return, and reviews Hrdlicka's contribution to the development of biological anthropology in the United States.

Hrdlicka emerges as an unlikeable person, racist, sexist, dismissive of native peoples, and known to contemporaries living at Larsen Bay as 'Hard Liquor,' although the reader is reminded that his attitudes were well within the norm for his time and culture. While they were poorly conducted by the standards of the 1990s, Hrdlicka's excavations revealed a longer and more complex prehistory of the area than had been previously thought. He concluded 